\title{
Mechanical properties of large-scale parallel bamboo strand lumber
}

\author{
under local compression
Ke Zhou ${ }^{1 a, 1 b}$, Haitao Li ${ }^{1 a, 1 b^{*}}$, Chaokun Hong ${ }^{1 a, 1 b}$, Dong Yang $^{1 a, 1 b}$, Usama Sayed ${ }^{1 a, 1 b}$, Rodolfo Lorenzo ${ }^{2}$, Ileana Corbi ${ }^{3}$, Ottavia Corbi ${ }^{3}$, Yingfeng $\mathrm{Zuo}^{4}$ \\ ${ }^{\text {la }}$ College of Civil Engineering, Nanjing Forestry University, Nanjing 210037, China; ${ }^{1 b}$ Joint International Research Laboratory of \\ Bio-composite Building Materials and Structures, Nanjing Forestry University, Nanjing 210037, China \\ ${ }^{2}$ University College London, London WC1E 6BT, UK. \\ ${ }^{3}$ University of Naples Federico II, Via Claudio 21,80133 Naples, Italy. \\ ${ }^{4}$ College of Materials Science and Engineering, Central South University of Forestry and Technology, Changsha 410004, China \\ *Corresponding author: Haitao LI, Professor, E-mail: 1haitao1982@126.com
}

\begin{abstract}
To study the local compression mechanical properties of large-scale parallel bamboo strand lumber (PBSL) structural elements, 20 specimens were tested considering two main influencing factors which are source position and compression direction. According to the experimental results, the failure of all specimens experienced elastic stage, elastic-plastic stage, and failure stage. The failure of the specimen was caused by the deformation perpendicular to the loading direction. For the middle specimens tangentially loaded, the failure belonged to ductile failure. For other group specimens, the failure belonged to quasi-brittle failure. The values for elastic modulus, stiffness, ultimate strength and Poisson's ratio of the end specimen were higher than those of the middle specimen. The values for elastic modulus, stiffness and Poisson's ratio of the specimens loaded tangentially were higher than those of the specimens loaded radially but the ultimate strength values for specimens loaded tangentially were lower than those for the specimens loaded radially. The ductility of the middle specimens was better than that of the end specimens. The load-displacement relationship model of the local compressive of PBSL was proposed based on the analysis. Based on the Ramberg-Osgood relation (ROR), the stress-strain relationship models for PBSL under local compression were proposed and compared with the test data.
\end{abstract}

Keywords: bamboo; local compression; damage mechanism; elastic modulus; ductility

\section{Introduction}

Similar to the timber [1-2], bamboo has a wide distribution, a great variety and excellent mechanical properties [3-6]. Besides, it takes a shorter harvest time for bamboo compared with trees. Therefore, the advantages of bamboo replacing wood for furniture, decoration and building structure are more and more obvious [7], which promotes the rapid development of the bamboo industry. The original bamboo materials couldn't meet the requirements of modern structure for the size and mechanical properties, promoting the development of engineered bamboo materials [8-9]. The common engineered bamboo materials are GluBam [10-12], parallel bamboo strand lumber (PBSL) [13], laminated bamboo lumber (LBL) [14-18]. Engineered bamboo materials could improve the shortcomings of original bamboo materials and could be used widely in the construction area.

Parallel bamboo strand lumber is made of processed bamboo fiber bundles [19]. With good mechanical performance, PBSL could meet the properties requirements of building structures. Ridzqo et al. [20] studied the fabrication of a novel composite board from bamboo fibers through a biologically binding mechanism by using fungal mycelium. Yu et al. [21] examined the effect of resin content and density on the properties of PBSL. Kumar et al. [22] investigated the effect of bamboo scrimber density on mechanical properties and water absorption properties. Li et al. [23-24] studied the basic mechanical properties of PBSL, as well as the compressive properties of PBSL considering different lengths and loading directions. Sharma et al. [25] examined the mechanical properties of PBSL and LBL and compared them with wood and wood products, which proved that the engineered bamboo has superior properties. Shangguan et al. [26-27] investigated the effect of different angles between load and grain and heat treatment on compressive properties of bamboo scriber and proposed the compressive strength model. 
Nugroho et al. [28-29] have performed a study to determine the suitability of the zephyr strand from Moso bamboo for structural composite board manufacture. Zhong et al. [30] studied the compressive strength of PBSL at different temperatures to provide the basis for its fire performance evaluation. Xu et al. [31] investigated the relationship between tensile and compressive stress-strain and failure mechanisms of PBSL at high temperatures. Malanit et al. [32] examined the physical and mechanical properties of bamboo scrimber made from an Asian bamboo. Zhou et al. [33-34] studied partial compression bearing capacity perpendicular and parallel to the grain of bamboo scrimber with small specimens, but the local compression properties of PBSL in two directions perpendicular to grain were not compared, and the research is only one side local compression and the size of the test specimen is not large enough to reflect the real situation. Besides the mechanical properties of materials, many scholars have also studied the structural components such as parallel bamboo strand lumber columns [35] and beams [36].

The engineered bamboo structure is similar to the wood structure. The local compression perpendicular to the grain of PBSL is a common stress state in the actual project, such as the connection between beams and columns, the connection between the main beam and the secondary beam, the use of PBSL as wood sleeper, cribbing, dunnage so on. At present, there have been some types of research on the local compression perpendicular to the grain of the timber. Van der Put [37] has given the theoretical explanation of the bearing strengths of locally loaded timber blocks, based on the equilibrium method of plasticity. Leijten et al. [38-40] have investigated the test methods for the local compression perpendicular to grain properties of wood perpendicular to the grain and compared with different national design codes. Madsen et al. [41] emphasized the influence of geometric conditions on the partial compression bearing capacity analyzed the stress diffusion by numerical simulation.

Yeh and Lin [42] investigated the effect of growth height on compressive strength for laminated bamboo lumber specimens with a cross-section of $30 \mathrm{~mm} \times 30 \mathrm{~mm}$. The compressive strengths in the lower growth height were smaller than those values in the upper growth height both for jointed and un-jointed specimens. Yeh and Lin [42] have shown a significant dependence of compressive strength on the growth height of the source bamboo. Their observation was made using small scale laminate bamboo specimens. This study will also investigate how the source bamboo growth height influences the compressive strength of full-scale PBSL structural members.

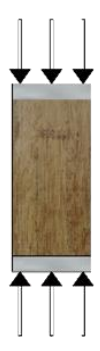

(a) Full section loading

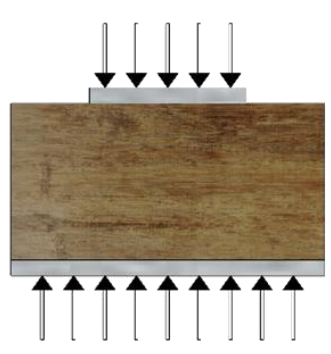

(b) Local compression on one side

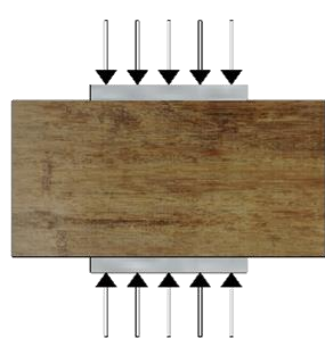

(c) Local compression on both sides

Fig. 1. Different compression situations

For the three compression situations as shown in Fig. 1. The situation shown in Fig.1a and Fig.1b has been studied, but it is still blank for the situation shown in Fig.1c. Thus, for the situation of Fig.1c, local compression tests about large-scale PBSL specimens were carried out in this paper considering the influencing factors of different parts and compression direction. Both the local stress-strain behaviour and the global load-displacement behaviour of the large PBSL specimens will be investigated. This is necessary because the global load-displacement is effected by splitting and delamination within the structural member, while the local stress-strain behaviour demonstrates the inelastic behaviour of the material itself. Detailed analysis and discussion about the test results have been done.

\section{Materials and Test Methods}

Harvested at the age of 3-4 years, Moso bamboo (Phyllostachys pubescent) was chosen to manufacture the specimens. As can be seen from Fig. 1, original bamboo tubes (Fig.2a) were split into $20 \mathrm{~mm}$ wide strips (Fig.2b) with the outer skin (epidermal) and inner cavity layer (pith peripheral) removed, and all culm strips were split into bamboo filament bundles (Fig.2c). All bundles were immersed in the resin pool and then pulled out for drying. Then 
the bundles were put into the molds (Fig.2d) and pressed together to form the blocks (Fig.2e) under $20^{\circ} \mathrm{C}$ with the press pressure about $62 \mathrm{MPa}$ to achieve the aim density value of $1200 \mathrm{~kg} / \mathrm{m}^{3}$. The molds with the blocks were then cured with the temperature about $135^{\circ} \mathrm{C}$ for 9 hours. The final moisture content was $8.22 \%$. Phenol glue was used to produce the PBSL specimens. The percentage of adhesive in the final composite material is $12 \%$.

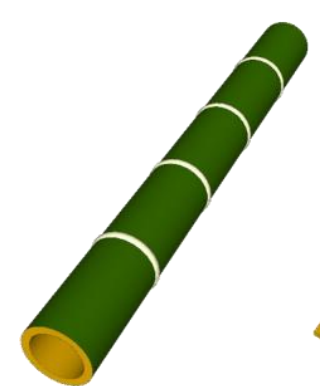

(a) Bamboo tubes

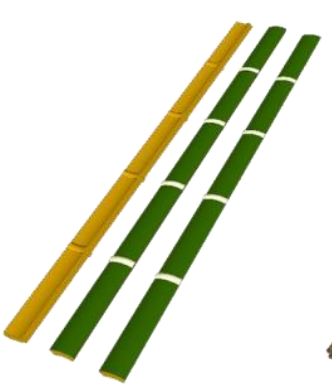

(b) Bamboo strips

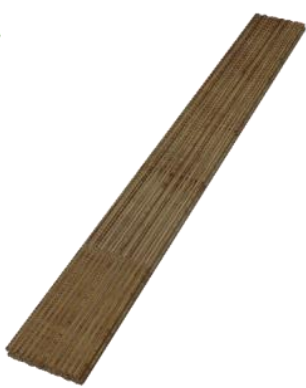

(c) Bamboo strand bundles

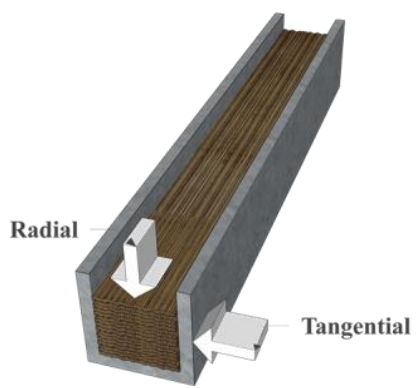

(d) Bundles in molds

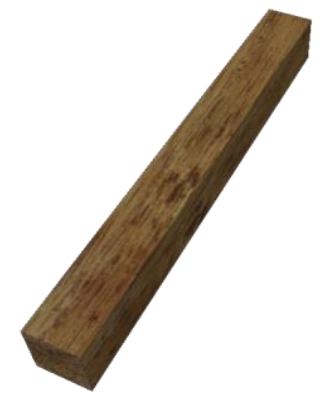

(e) PBSL

Fig. 2. The production process of PBSL.

Twenty specimens were cut from the PBSL, with a length of $200 \mathrm{~mm}$ and a section of $100 \mathrm{~mm} \times 100 \mathrm{~mm}$. The truncation position is in the middle and the end part. Bamboo strand bundles in the end part are the upper position of the original bamboo. The specimens were divided into four groups based on different parts and different loading directions and each group contains 5 identical specimens. The average density of the end specimens is $1.21 \mathrm{~g} / \mathrm{cm}^{3}$ and the middle specimens are $1.24 \mathrm{~g} / \mathrm{cm}^{3}$. Fig. 3. shows the specimens from two main parts and loading directions. Detailed information about the specimens could be seen in Table 1.

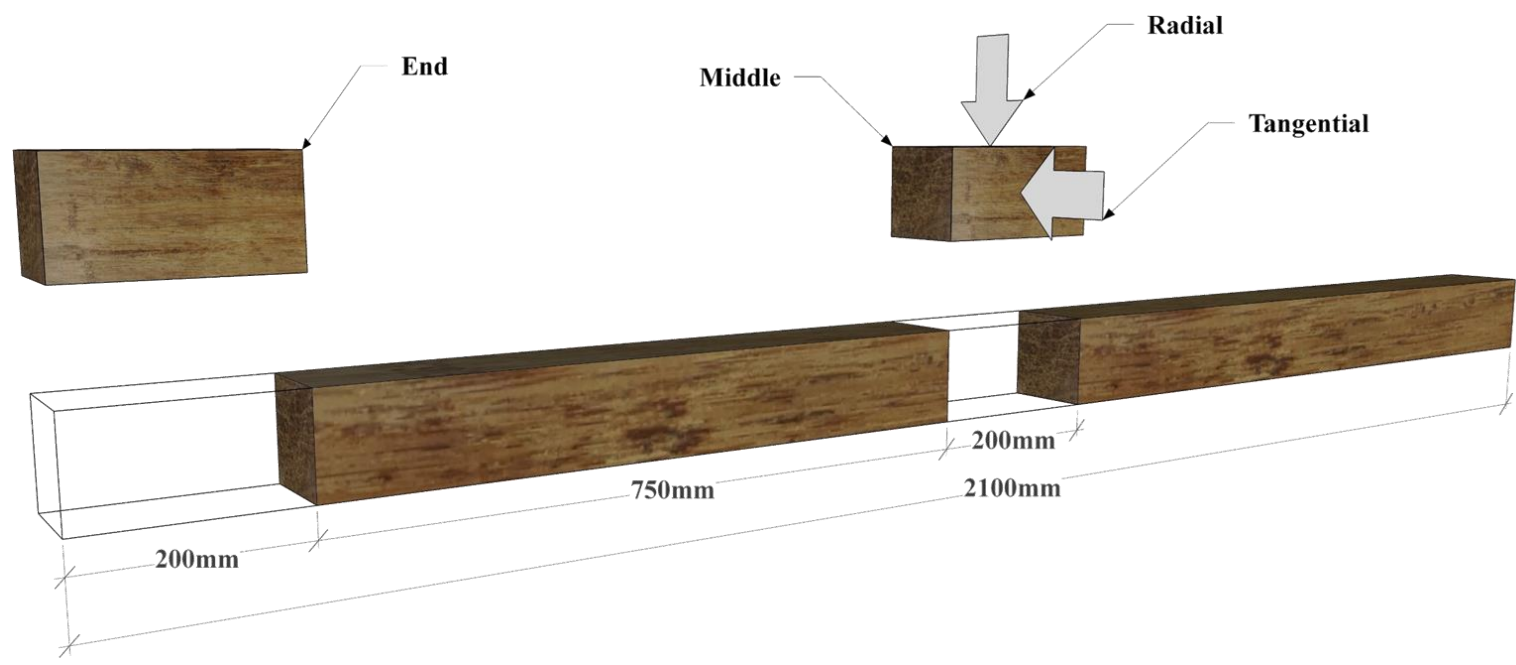

Fig. 3. Diagram of different parts and loading directions

Table 1 The information for the specimens

\begin{tabular}{llllll}
\hline Group & Material location & Loading direction & Width $(\mathrm{mm})$ & Height $(\mathrm{mm})$ & Length $(\mathrm{mm})$ \\
\hline ET & End & Tangential & 100 & 100 & 200 \\
ER & End & Radial & 100 & 100 & 200 \\
MT & Middle & Tangential & 100 & 100 & 200 \\
MR & Middle & Radial & 100 & 100 & 200 \\
\hline
\end{tabular}

Notes: ET represents the specimen cut from the end part of the original PBSL blocks and loaded tangentially; ER represents the specimen cut from the end part of the original PBSL blocks and loaded radially; MT represents the specimen cut from the middle part of the original PBSL blocks and loaded tangentially; MR represents the specimen cut from the middle part of the original PBSL blocks and loaded radially.

The local bearing area of the test specimen is $100 \mathrm{~mm} \times 100 \mathrm{~mm}$, and $100 \mathrm{~mm} \times 150 \mathrm{~mm} \times 30 \mathrm{~mm}$ stainlesssteel blocks were set up on the top and bottom of the specimen. By loading on stainless-steel blocks to achieve the 
purpose of local loading compression, as shown in Fig. 5. The displacement was measured between the opposing faces of the loading plates by using laser displacement sensors.

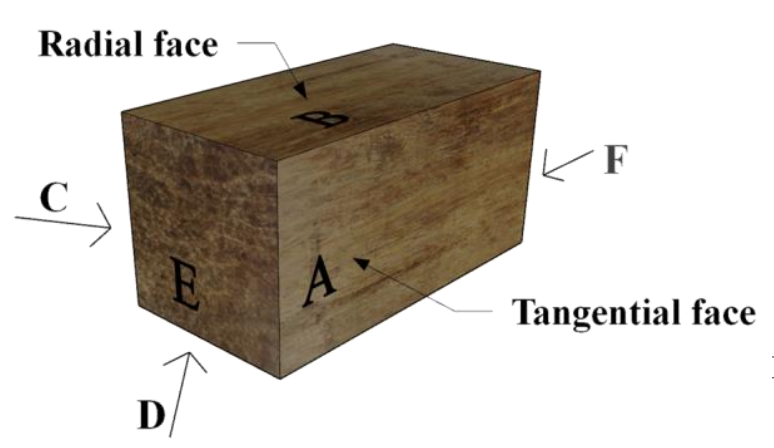

Fig. 4. Schematic diagram of specimens

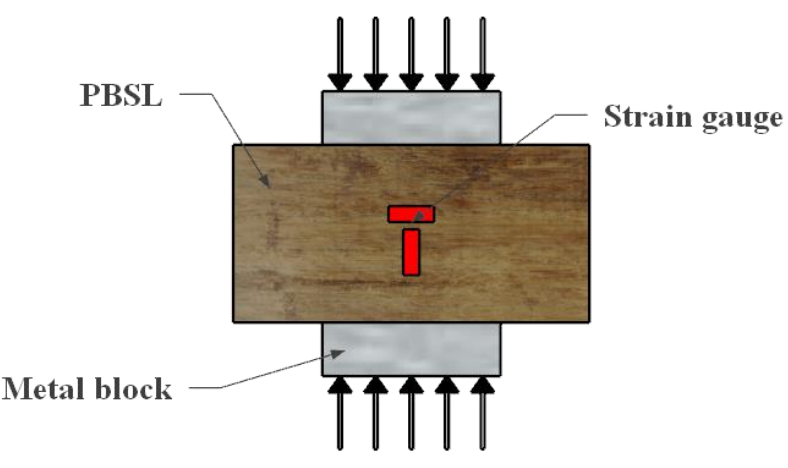

Fig. 5. Loading method

The test was performed using a microcomputer-controlled electro-hydraulic servo universal testing machines with a capacity of $2000 \mathrm{kN}$ and a TDS Data Acquisition System. The total time is controlled within 8 to 10 minutes from the start of loading and the speed of loading is $2 \mathrm{~mm} / \mathrm{min}$. To describe the experimental phenomenon conveniently, all faces of the specimens are numbered, and the four sides are A, B, C, D and two cross-sections are E, F; the pressurized faces are B and D. Specimen radially loaded is shown in the fig. 3. For specimens tangentially loaded, tangential faces are marked as $\mathrm{B}$ and $\mathrm{D}$ and radial faces are marked as A and $\mathrm{C}$.

\section{Failure Phenomena Analysis}

The load-displacement curves obtained from the tests are shown in Fig. 6. The failure of the specimen could be divided into three stages: elastic stage, elastic-plastic stage, and failure stage. When a load value of all specimens increased to about $40 \%$ of the ultimate load, the specimens began to enter into the elastic-plastic stage. At the end of the elastic-plastic stage, about $90 \%$ of the ultimate load, an audible noise could be heard before visual cracks appeared on the surface. With the development of cracks, the specimens gradually broke down. The failure model of the specimens under the same loading direction was similar. The failure of the specimens was mainly caused by the deformation perpendicular to the loading direction.

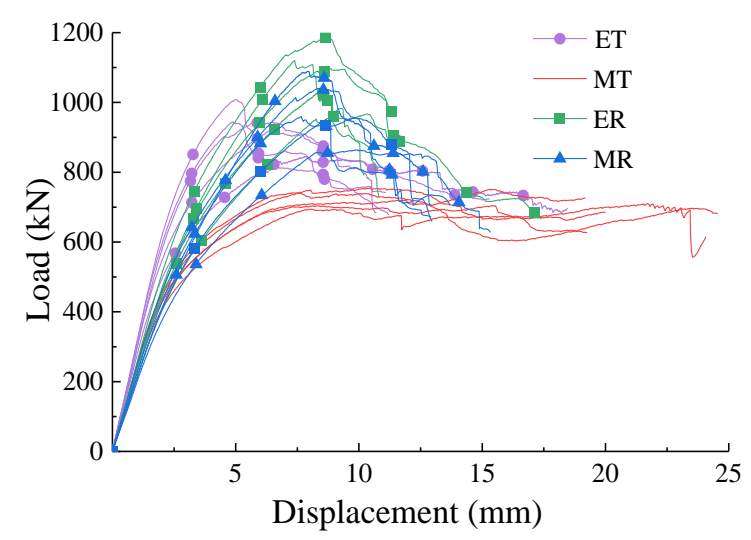

Fig. 6. Load-displacement curves

\subsection{The failure of specimens tangentially loaded}

There are two main failure models for specimens tangentially loaded, both of which belong to strength failure. The failure model I is shown in Fig. 7. At the initial stage of loading, the specimens were in the elastic stage, and the vertical strain for face $A$ and $C$ were equal to each other without crack on the specimens. As the specimen entered into the elastic-plastic stage, plastic deformation occurred at the contact edge between the specimen and the upper and lower stainless-steel blocks while there was no obvious change on the surface of the specimens. When the load 
increased to about $90 \%$ of the ultimate load, cracks began to appear on the surface of the specimen. The horizontal cracks appeared firstly near the apex corner of face B and D, as shown in Fig. 7. (c) and (f). With the increase of load, the cracks developed, and the vertical cracks appeared near the apex corner of cross-section $\mathrm{E}$ and $\mathrm{F}$. The vertical cracks developed to the middle of the specimen, and finally became two main vertical bending cracks. The cracks developed towards the middle and the distance of the two main cracks became smaller as shown in Fig. 7 . (a) and (d). It can be seen from the damaged specimen that the deformation of the compression area in the middle of the specimen was obvious. Several main cracks could be seen from the side parts for face B and D, as shown in Fig. 7. (c) and (f), and there is no obvious failure on face $A$ and $C$ of the specimen, as shown in Fig. 7. (b) and (e).

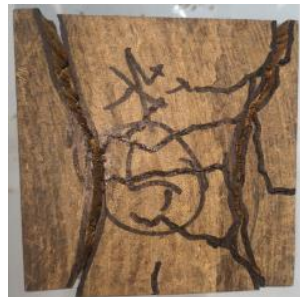

(a) Face E

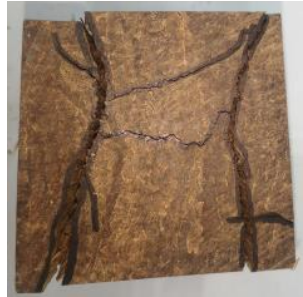

(d) Face F

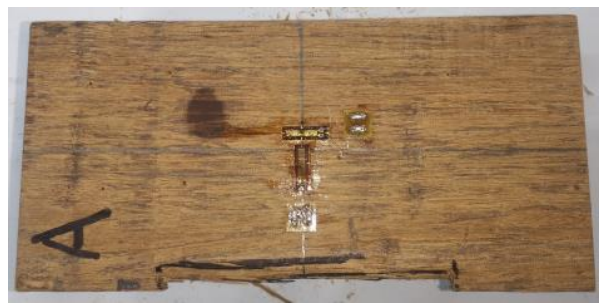

(b) Face A

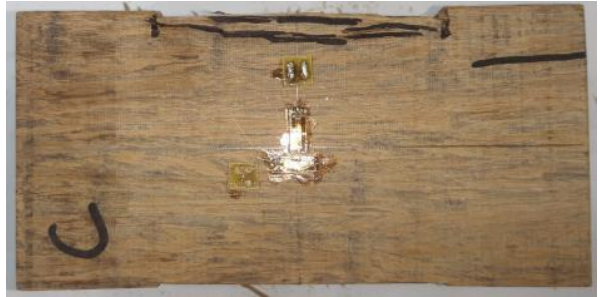

(e) Face C

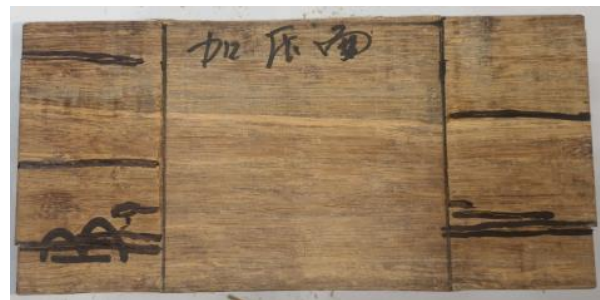

(c) Face B

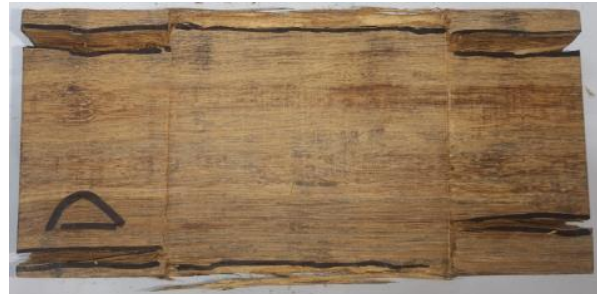

(f) Face D

Fig. 7. Failure model I(ET-5)

The failure model II is similar to model I, but the vertical deformation of the specimen for failure model II is more obvious than that for failure model I as shown in Fig. 8. (b) and (e). There are more horizontal cracks on the compression faces B and D as shown in Fig. 8. (c) and (f). There was one more vertical main crack in the middle of cross-section $\mathrm{E}$ and $\mathrm{F}$ for failure model II, and the failure of the specimen was mainly caused by these three cracks, as shown in Fig. 8. (a) and (d).

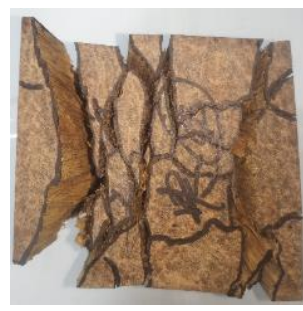

(a) Face E

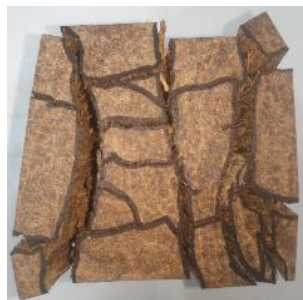

(d) Face F

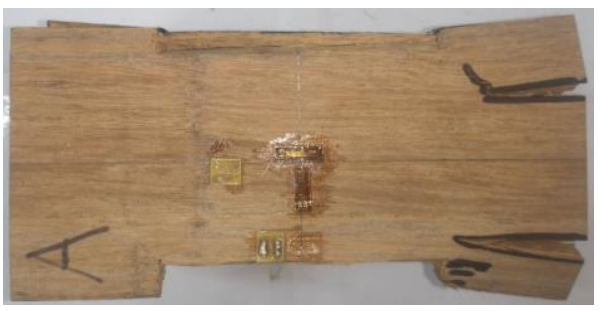

(b) Face A

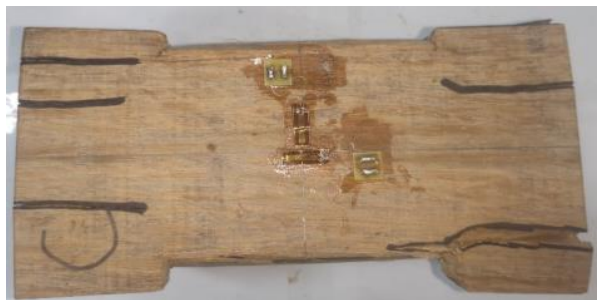

(e) Face C

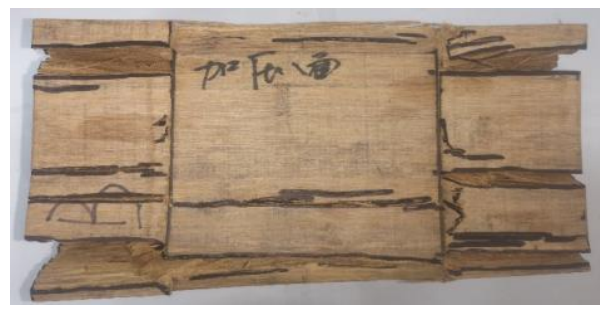

(c) Face B

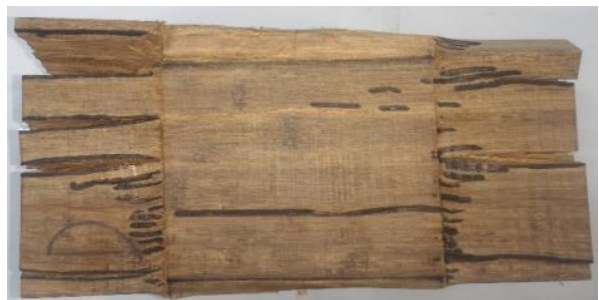

(f) Face D

Fig. 8. Failure model II (MT-4)

The crack developed inside of the specimen. The failure of specimens tangentially loaded was mainly caused by the horizontal deformation perpendicular to the loading direction and grain direction as shown in Fig. 9 .

As shown in table 2, most of the specimens from group ET belong to failure model I while most of the 
specimens from group MT belong to failure model II. Bamboo strand bundles for group ET were from the upper position of the original bamboo compared with those for group MT. As the former studies have discovered mechanical differences between small specimens sourced from different growth portions, the differences also existed in the large-scale parallel bamboo strand lumber specimens. Due to the high density of bamboo fibers for the bundles from the upper position, the strength for group ET are stronger than that for group MT and the main failure models were also different for two groups.

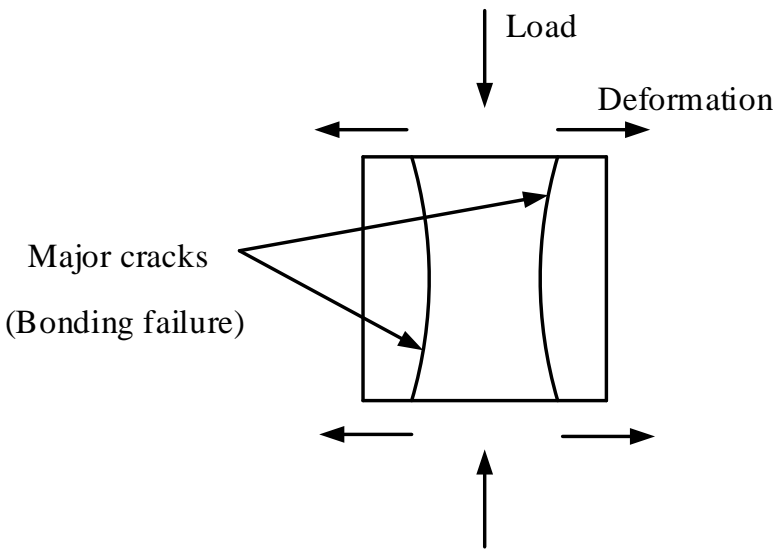

(a) Failure diagram of model I

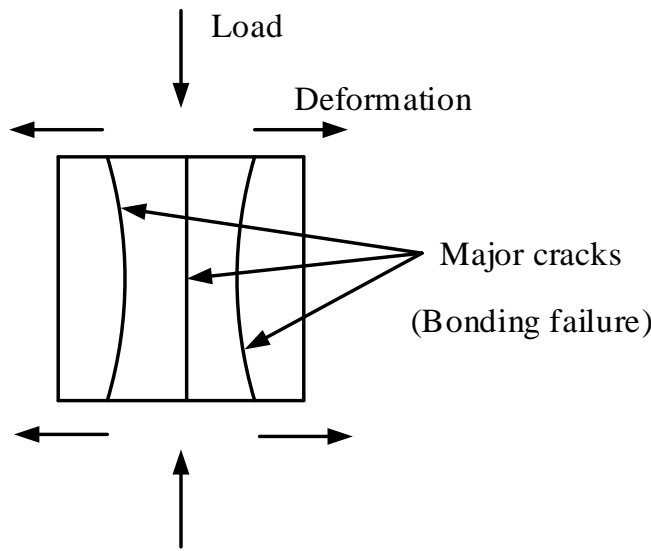

(b) Failure diagram of model II

Fig. 9. Deformation leading to failure

\subsection{The failure of specimens radially loaded}

Two main failure models of specimens radially loaded were also strength failure. The failure model III is shown in Fig. 10. At the initial stage of loading, it is the same as the specimens tangentially loaded. When the load increased to about $90 \%$ of the ultimate load, the specimen began to damage. The vertical cracks first appeared in the middle of face $\mathrm{A}$ and $\mathrm{C}$ and the apex corner of sections $\mathrm{E}$ and $\mathrm{F}$. The crack of sections $\mathrm{E}$ and $\mathrm{F}$ finally showed a ' $\mathrm{V}$ ' shape as shown in Fig. 10.

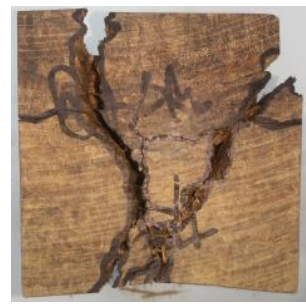

(a) Face $\mathrm{E}$

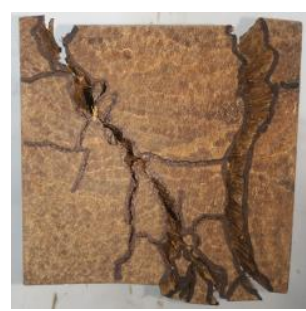

(d) Face $\mathrm{F}$

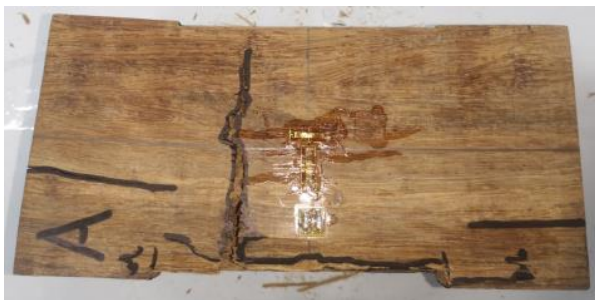

(b) Face A

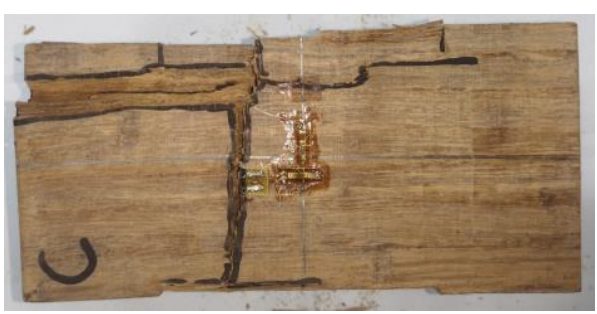

(e) Face C

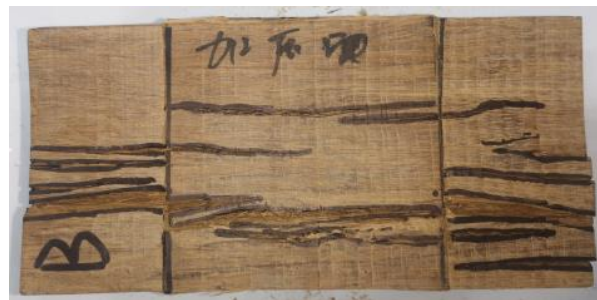

(c) Face B

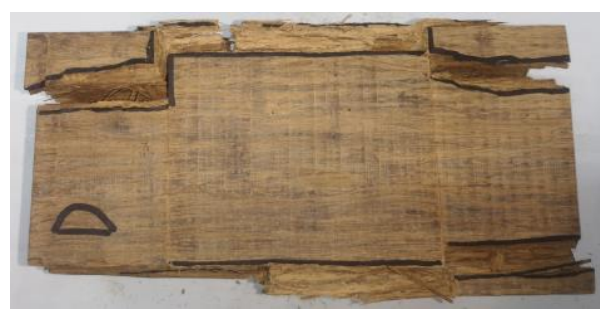

(f) Face D

Fig. 10. Failure model III (ER-4)

The cross-section of the failure model IV was similar to the failure of specimens tangentially loaded as shown in Fig. 11. There were two main vertical cracks on face $\mathrm{E}$ and F. Similar cracks appeared on face A and C as failure model III. The failure of the specimen was caused by the falling off and fracture of face A and C. 


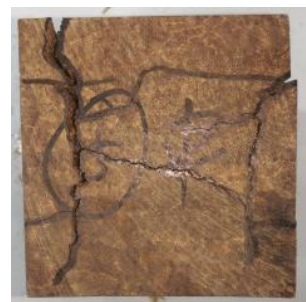

(a) Face E

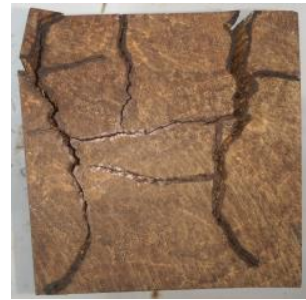

(d) Face F

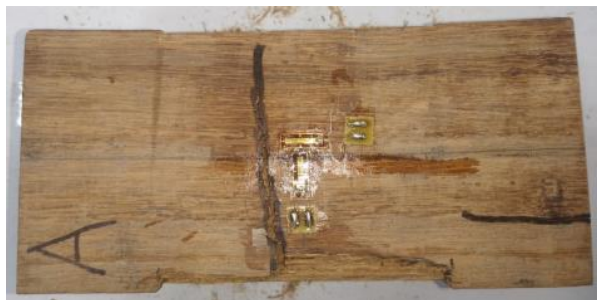

(b) Face A

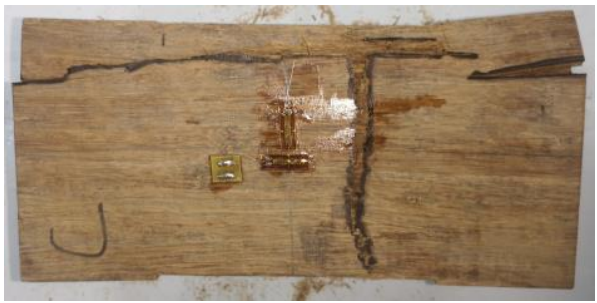

(e) Face C

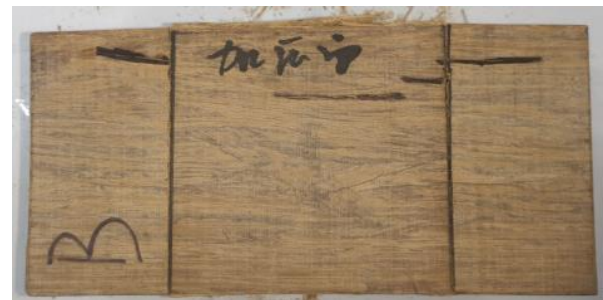

(c) Face B

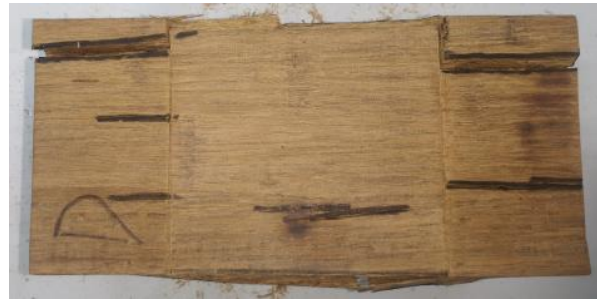

(f) Face D

Fig. 11. Failure model IV (MR-5)

The two failure of the specimen radially loaded have obvious signs, and the degree of failure is more serious than the specimen tangentially loaded. The failure was caused by the development of vertical cracks on cross-section $\mathrm{E}, \mathrm{F}$ and face $\mathrm{A}$ and $\mathrm{C}$, which leaded to the partial falling off and fracture of faces $\mathrm{A}$ and $\mathrm{C}$. The two failure models were not only caused by the horizontal deformation perpendicular to the loading direction and bamboo fiber direction but also the horizontal deformation parallel to bamboo fiber direction shown in Fig. 12.

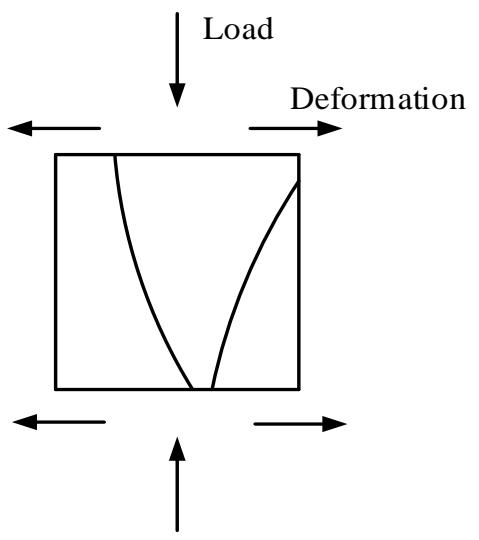

(a) Failure diagram of model III

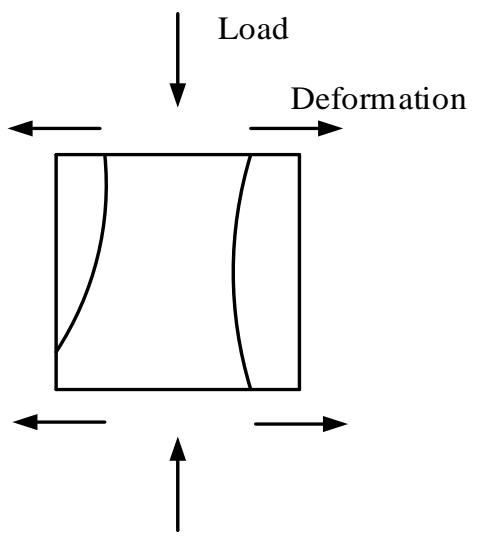

(b) Failure diagram of model IV

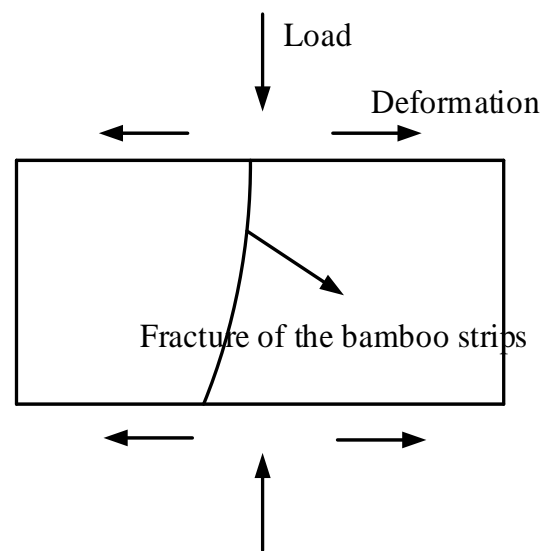

(c) Failure diagram of both models

Fig. 12. Deformation leading to failure

Comparing the main failure models of specimens loaded by different directions, the failure of the specimens tangentially loaded was mainly due to the bonding failure between the bamboo fibers, which caused the face A and $\mathrm{C}$ to partly fall off. The bamboo fibers of the specimens tangentially loaded did not break in the length direction.

The failure of the specimen radially loaded was not only the bonding failure between the bamboo fibers but also the fracture of bamboo fibers which could be seen from the vertical cracks on face $A$ and $C$, so the failure degree of specimens radially loaded is deeper.

\section{Combined Analysis}

\subsection{Data comparison and analysis}

Table 2 shows the experimental results. 
Table 2 The experimental results of specimens

\begin{tabular}{|c|c|c|c|c|c|c|c|c|c|}
\hline Specimen & $\rho\left(\mathrm{g} / \mathrm{cm}^{3}\right)$ & $E(\mathrm{MPa})$ & $k(\mathrm{kN} / \mathrm{mm})$ & $f(\mathrm{MPa})$ & $v$ & $S_{\mathrm{cu}}(\mathrm{mm})$ & $s_{\mathrm{cy}}(\mathrm{mm})$ & $\mu$ & Failure model \\
\hline ET-1 & 1.23 & 6083 & 313 & 100.8 & 0.24 & 5.13 & 2.08 & 2.46 & I \\
\hline ET-2 & 1.25 & 5103 & 298 & 92.5 & 0.26 & 6.70 & 1.51 & 4.43 & I \\
\hline ET-3 & 1.20 & 5260 & 316 & 94.4 & 0.24 & 5.08 & 1.65 & 3.07 & II \\
\hline ET-4 & 1.22 & 5472 & 295 & 94.7 & 0.24 & 5.83 & 1.73 & 3.36 & I \\
\hline ET-5 & 1.23 & 5860 & 277 & 84.0 & 0.25 & 6.79 & 1.56 & 4.36 & I \\
\hline Mean & 1.23 & 5556 & 300 & 93.3 & 0.25 & 5.91 & 1.71 & 3.54 & \\
\hline SDV & 0.0162 & 366 & 14.02 & 5.41 & 0.0080 & 0.735 & 0.202 & 0.760 & \\
\hline $\mathrm{COV}$ & 0.0133 & 0.0659 & 0.0468 & 0.0580 & 0.0325 & 0.125 & 0.118 & 0.215 & \\
\hline $\mathrm{CHV}$ & 1.19 & 4818 & 272 & 82.4 & 0.23 & 4.42 & 1.30 & 2.01 & \\
\hline MT-1 & 1.16 & 4396 & 251 & 73.9 & 0.24 & 7.45 & 1.35 & 5.54 & II \\
\hline MT-2 & 1.15 & 4117 & 250 & 74.8 & 0.23 & 8.05 & 1.68 & 4.79 & II \\
\hline MT-3 & 1.20 & 4026 & 240 & 69.3 & 0.23 & 8.11 & 1.91 & 4.25 & I \\
\hline MT-4 & 1.23 & 3765 & 251 & 70.0 & 0.25 & 7.06 & 1.66 & 4.24 & II \\
\hline MT-5 & 1.22 & 3631 & 245 & 70.3 & 0.25 & 7.11 & 1.51 & 4.72 & II \\
\hline Mean & 1.19 & 3987 & 247 & 71.7 & 0.24 & 7.56 & 1.62 & 4.71 & \\
\hline SDV & 0.0319 & 269 & 4.32 & 2.24 & 0.0089 & 0.449 & 0.187 & 0.475 & \\
\hline $\mathrm{COV}$ & 0.0267 & 0.0675 & 0.0175 & 0.0312 & 0.0373 & 0.0594 & 0.115 & 0.101 & \\
\hline $\mathrm{CHV}$ & 1.13 & 3445 & 239 & 67.1 & 0.22 & 6.65 & 1.25 & 3.75 & \\
\hline ER-1 & 1.23 & 3726 & 225 & 96.4 & 0.22 & 8.28 & 2.32 & 3.57 & III \\
\hline ER-2 & 1.32 & 4253 & 235 & 118.6 & 0.23 & 8.63 & 2.15 & 4.02 & IV \\
\hline ER-3 & 1.27 & 3781 & 238 & 112.0 & 0.20 & 7.39 & 2.30 & 3.22 & III \\
\hline ER-4 & 1.23 & 3650 & 231 & 109.6 & 0.20 & 8.34 & 2.41 & 3.46 & III \\
\hline ER-5 & 1.22 & 3610 & 230 & 102.9 & 0.20 & 8.46 & 2.01 & 4.20 & IV \\
\hline Mean & 1.25 & 3804 & 232 & 107.9 & 0.21 & 8.22 & 2.24 & 3.69 & \\
\hline SDV & 0.0372 & 232 & 4.45 & 7.63 & 0.0126 & 0.432 & 0.141 & 0.363 & \\
\hline $\mathrm{COV}$ & 0.0297 & 0.0610 & 0.0192 & 0.0708 & 0.0602 & 0.0525 & 0.0632 & 0.0981 & \\
\hline $\mathrm{CHV}$ & 1.18 & 3336 & 223 & 92.5 & 0.18 & 7.35 & 1.95 & 2.96 & \\
\hline MR-1 & 1.25 & 3504 & 211 & 108.9 & 0.19 & 7.97 & 1.99 & 4.01 & IV \\
\hline MR-2 & 1.27 & 3366 & 217 & 104.0 & 0.19 & 8.42 & 1.76 & 4.78 & III \\
\hline MR-3 & 1.20 & 2982 & 212 & 94.3 & 0.20 & 9.67 & 1.87 & 5.18 & III \\
\hline MR-4 & 1.20 & 3194 & 198 & 85.8 & 0.21 & 8.28 & 2.02 & 4.10 & IV \\
\hline MR-5 & 1.20 & 3180 & 224 & 95.9 & 0.17 & 7.67 & 1.88 & 4.08 & IV \\
\hline Mean & 1.22 & 3245 & 212 & 97.8 & 0.19 & 8.40 & 1.90 & 4.43 & \\
\hline SDV & 0.0301 & 178 & 8.55 & 8.02 & 0.0133 & 0.685 & 0.0931 & 0.468 & \\
\hline $\mathrm{COV}$ & 0.0246 & 0.0547 & 0.0402 & 0.0820 & 0.0691 & 0.0815 & 0.0489 & 0.106 & \\
\hline $\mathrm{CHV}$ & 1.16 & 2887 & 195 & 81.6 & 0.17 & 7.02 & 1.72 & 3.49 & \\
\hline
\end{tabular}

Notes: In Table 1, $\rho$ is density; $E$ is elastic modulus (Select the point calculation when the strain is 0.005.); $k$ is stiffness (Select the point calculation when the axial displacement is $1.5 \mathrm{~mm}$.); $f$ is local bearing ultimate strength perpendicular to grain; $v$ is Poisson's ratio (It's the Poisson's ratio in the elastic stage.), $s_{\mathrm{cu}}$ is the ultimate displacement, $s_{\mathrm{cy}}$ is the displacement for the yield point (The yield point is the point at which the stiffness begins to decrease. As shown in Fig 13, When the difference is between 0 and $20 \mathrm{kN}$, the corresponding point can be selected as the yield point.), $\mu$ is ductility coefficient (The displacement corresponding to the ultimate load divided by the displacement corresponding to the yield point, $s_{\mathrm{cu}} / s_{\mathrm{cy}}$ ), SDV is the standard deviation; COV is the coefficient of variation (SDV/Mean); CHV means characteristic value, calculated on the basis that $95 \%$ of samples exceed the characteristic value (Mean-2.015 × SDV). 


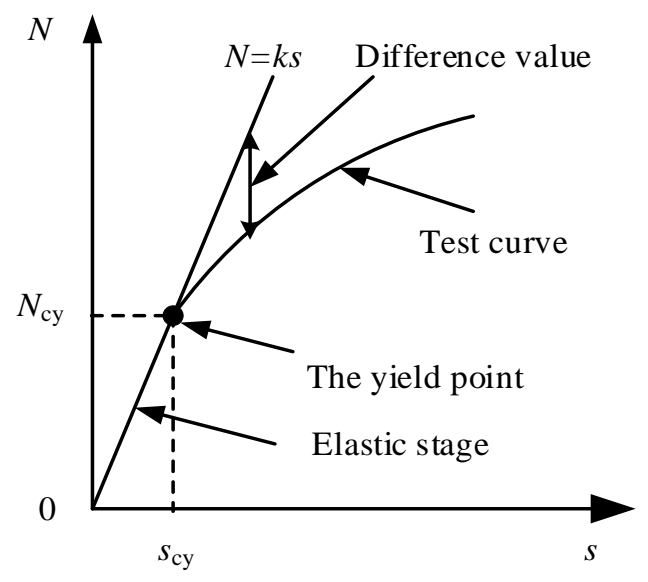

Fig. 13. Determination of yield point

From the results in table 1, the coefficient of variation of elastic modulus, stiffness, ultimate strength and Poisson's ratio were all less than 0.1 , and the data are stable. The relationship between the elastic modulus, stiffness, ultimate strength and Poisson's ratio of each group of specimens can be expressed by formula (1) to formula (4):

$$
\begin{gathered}
E_{\mathrm{ET}}=1.393 E_{\mathrm{MT}}=1.460 E_{\mathrm{ER}}=1.712 E_{\mathrm{MR}} \\
k_{\mathrm{ET}}=1.137 k_{\mathrm{MT}}=1.219 k_{\mathrm{ER}}=1.391 k_{\mathrm{MR}} \\
f_{\mathrm{ET}}=1.227 f_{\mathrm{MT}}=0.890 f_{\mathrm{ER}}=1.009 f_{\mathrm{MR}} \\
v_{\mathrm{ET}}=1.045 v_{\mathrm{MT}}=1.277 v_{\mathrm{ER}}=1.353 v_{\mathrm{MR}}
\end{gathered}
$$

Fig.14. Compared the elastic modulus, rigidity, ultimate strength, Poisson's ratio and ductility coefficient of each group of specimens.

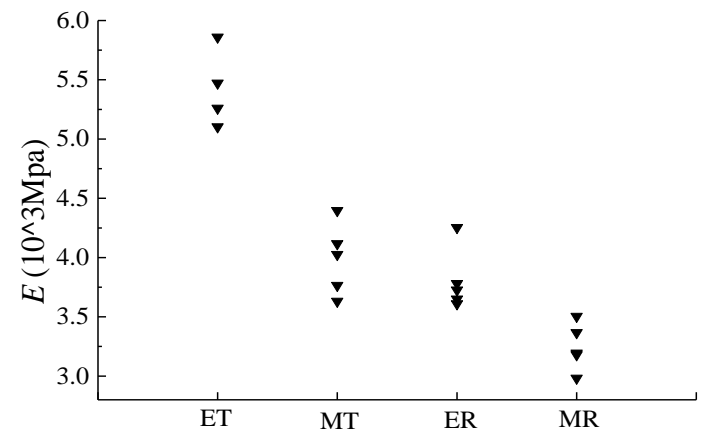

(a) Comparison of elastic modulus

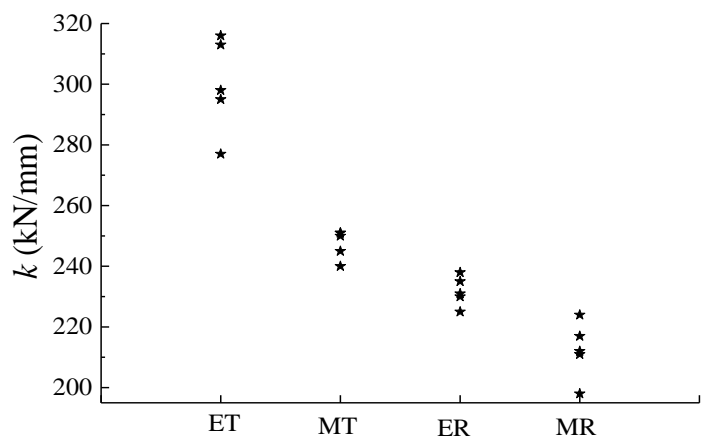

(b) Comparison of stiffness 


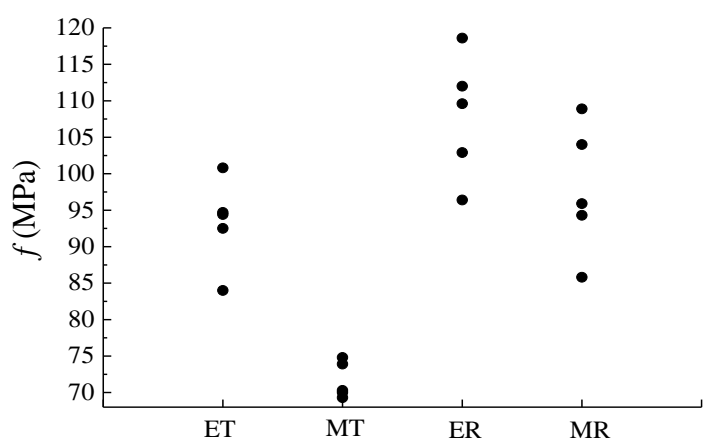

(c) Comparison of ultimate strength

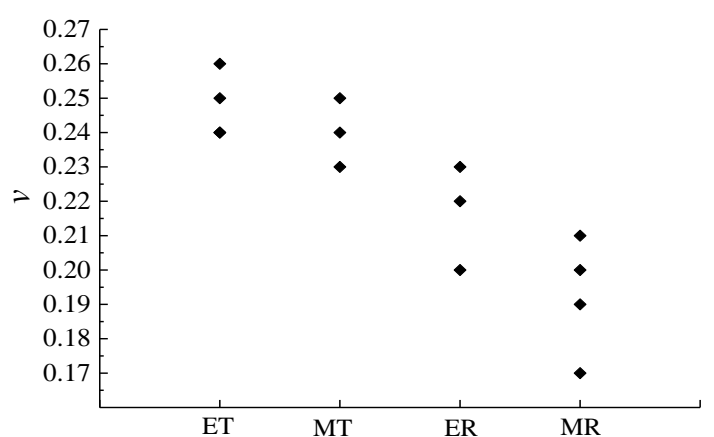

(d) Comparison of Poisson's ratio

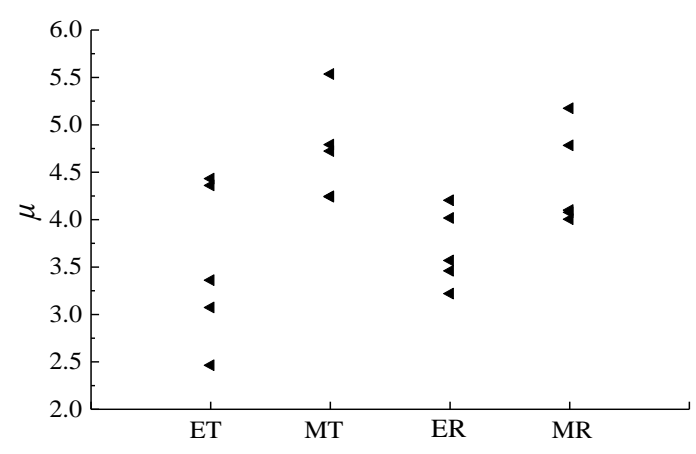

(e) Comparison of ductility coefficient

Fig.14. Comparison of experimental results

It could be found that for ultimate strength, elastic modulus, Poisson's ratio, stiffness, the end specimens were higher than the middle specimens. The elastic modulus, Poisson's ratio and stiffness of the specimens tangentially loaded were higher than that for specimens radially loaded, and the ultimate strength was lower than that radially loaded. The ductility of the middle specimens was better than that of the end specimens. There was little difference in the ductility of specimens loaded in different directions.

\subsection{Load-displacement curves}

The load-displacement curves obtained from the tests are shown in Fig. 6. All specimens went through the elastic stage, elastic-plastic stage, and failure stage. In the elastic stage, the load-displacement curves were straight, and the rigidity was stable. The stiffness of the specimen decreases during the elastic-plastic phase, and the curve occurred deviation. In the failure stage, the bearing capacity of the middle specimen tangentially loaded did not decrease and the ultimate load remained unchanged. The bearing capacity of the other three groups of specimens decreased in the failure stage. The stiffness of the four groups of specimens in the elastic stage slightly deviated. When the vertical displacement of the specimens reached $1.5-2.5 \mathrm{~mm}$, the specimens entered the elastic-plastic stage, and when the vertical displacement reached $5-9 \mathrm{~mm}$, the specimens entered the failure stage.

Combined with the failure model of the specimens, the load-displacement relationship of the four groups of specimens could be expressed by a function model as shown in Fig. 15. 


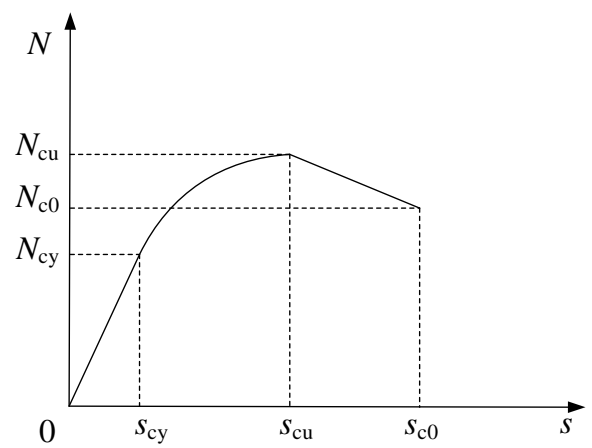

Fig. 15. Load-displacement model

The load-displacement model could be expressed by formula (5):

$$
N= \begin{cases}k s & \left(0 \leq s<s_{\mathrm{cy}}\right) \\ \lambda_{1} s^{2}+\lambda_{2} s+\lambda_{3} & \left(s_{\mathrm{cy}} \leq s<s_{\mathrm{cu}}\right) \\ N_{\mathrm{cu}}-\alpha k\left(s-s_{\mathrm{cu}}\right) & \left(s_{\mathrm{cu}} \leq s<s_{\mathrm{c} 0}\right)\end{cases}
$$

Where $s_{\mathrm{cy}}$ is the displacement for the yield point; $N_{\mathrm{cy}}$ is the load for the yield point; $s_{\mathrm{cu}}$ is the ultimate displacement; $N_{\mathrm{cu}}$ is the ultimate load; $s_{\mathrm{c} 0}$ is maximum displacement when the specimen is broken; $N_{\mathrm{c} 0}$ is the load corresponding to $s_{\mathrm{c} 0} ; k$ is stiffness; $k, \lambda_{1}, \lambda_{2}, \lambda_{3}, \alpha$ could be solved by formula (6) to formula (10):

$$
\begin{aligned}
& k=\frac{N_{\mathrm{cy}}}{s_{\mathrm{cy}}} \\
& \lambda_{1}=\frac{N_{\mathrm{cy}}-N_{\mathrm{cu}}}{\left(s_{\mathrm{cy}}-s_{\mathrm{cu}}\right)^{2}} \\
& \lambda_{2}=\frac{2 s_{\mathrm{cu}}\left(N_{\mathrm{cy}}-N_{\mathrm{cu}}\right)}{\left(s_{\mathrm{cy}}-s_{\mathrm{cu}}\right)^{2}} \\
& \lambda_{3}=N_{\mathrm{cy}}-\lambda_{1} s_{\mathrm{cy}}{ }^{2}-\lambda_{2} s_{\mathrm{cy}} \\
& \alpha=\frac{N_{\mathrm{c} 0}-N_{\mathrm{cu}}}{k\left(s_{\mathrm{c} 0}-s_{\mathrm{cu}}\right)}
\end{aligned}
$$

The comparison between the test results of each group of specimens and the theoretical values of the model as shown in Fig. 16. The model can represent the load-displacement relationship.

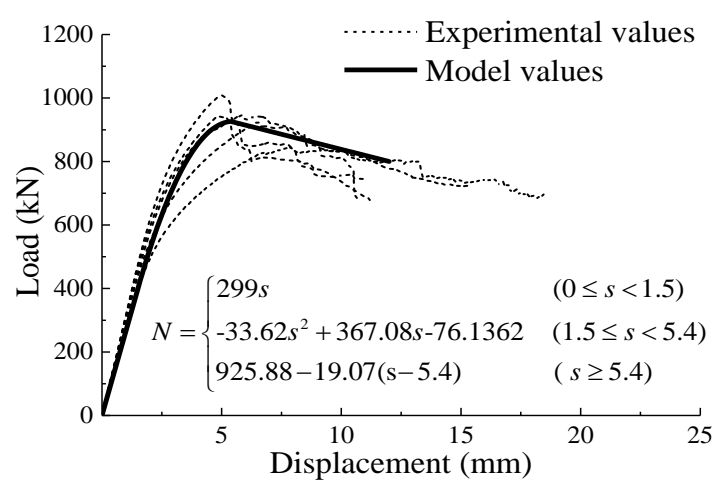

(a) Group ET

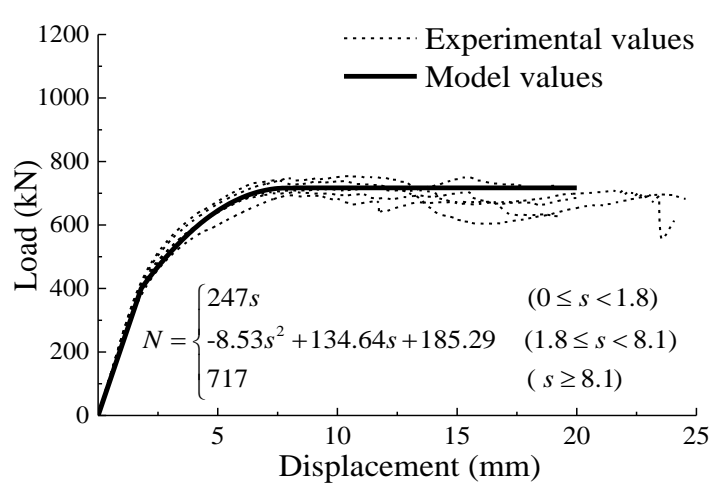

(b) Group MT 


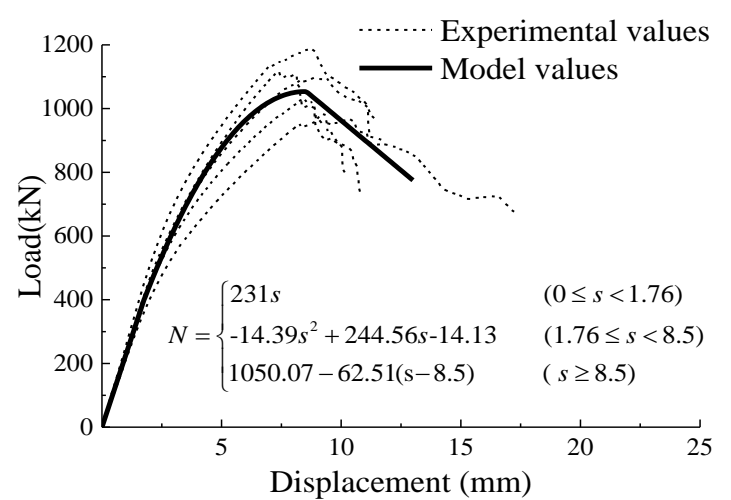

(c) Group ER

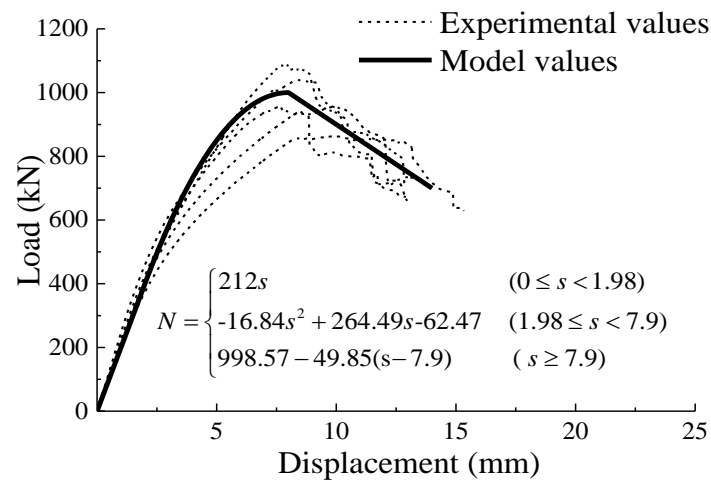

(d) Group MR

Fig. 16. Comparison between experimental values and model values

From the load-displacement curves and models of four groups of specimens, it could be seen that in the elastic stage, the stiffness of the end specimen was greater than that of the middle specimen, and that of the specimen tangentially loaded was greater than that of the specimen radially loaded. The ultimate load of the end specimen was greater than that of the middle specimen, and that of the specimen radially loaded was greater than that of the specimen tangentially loaded.

The falling speed of the load in the failure stage reflects the failure degree of the specimen. From the loaddisplacement model, it could be seen that the failure of the end specimen was more serious than that of the middle specimen, and the failure of the specimen loaded radially was more serious than that of the specimen loaded tangentially. It was consistent with the failure models. For the middle specimen tangentially loaded, the failure degree was least, and the specimen was compacted during the loading process so that the bearing capacity of this group of specimens in the failure stage could remain unchanged within a certain deformation range.

\subsection{Stress-strain curves}

The stress-strain curves obtained from the tests were shown in Fig. 17. The stress-strain curves were similar to the load-displacement curves in the elastic stage and the elastic-plastic stage. As the cracks appeared in the specimen at the end of the elastic-plastic stage, the internal force was redistributed. When the cracks appeared and developed in the specimen, most of the strain gauges stopped working or the measured values couldn't reflect the true strain of the specimen. Therefore, the stress-strain curves had no obvious decline stage. It could be found that the vertical ultimate strain of the specimens loaded radially was larger than that of the specimens loaded tangentially.

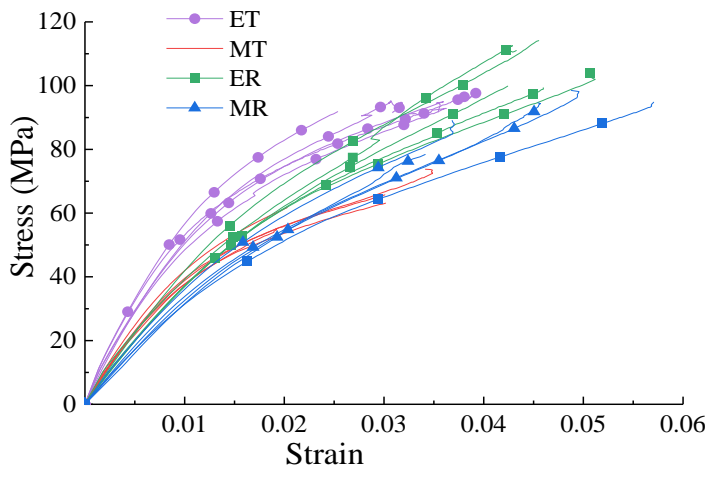

Fig. 17. Stress-strain curves

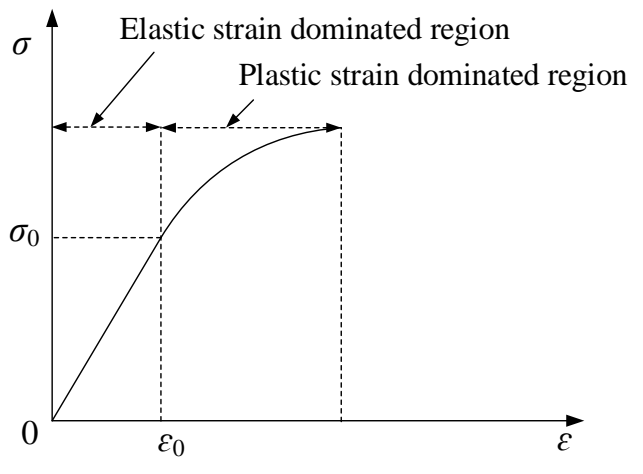

Fig. 18. Ramberg-Osgood Model

It could be seen from Fig. 17. that there was no obvious yield point in the stress-strain curves. Ramberg-Osgood relation (ROR) could be used to express the stress-strain relationship [43], as shown in Fig. 18. In the original form of the ROR model, the total strain could be expressed as the sum of elastic strain $\left(\varepsilon_{\mathrm{e}}\right)$ and plastic $\operatorname{strain}\left(\varepsilon_{\mathrm{p}}\right)$. 


$$
\varepsilon=\frac{\sigma}{E}+K\left(\frac{\sigma}{E}\right)^{n}
$$

By substituting the stress $\left(\sigma_{0}\right)$ and strain $\left(\varepsilon_{0}\right)$ at any point in the elastic stage into the formula (11), the elastic modulus $(E)$ could be eliminated and the ROR model could be obtained in formula (12).

$$
\frac{\varepsilon}{\varepsilon_{0}}=\frac{\sigma}{\sigma_{0}}+\alpha\left(\frac{\sigma}{\sigma_{0}}\right)^{n}
$$

Where $\alpha$ and $n$ are undetermined parameters which could be determined by fitting experimental values.

The stress-strain relationship of each group of specimens obtained by nonlinear fitting was shown in Fig. 19. ROR model could better express the stress-strain relationship of PBSL under local compression.

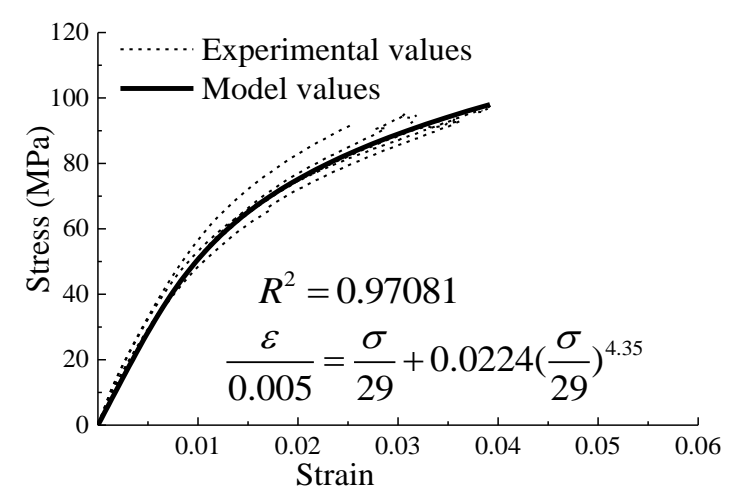

(a) Group ET

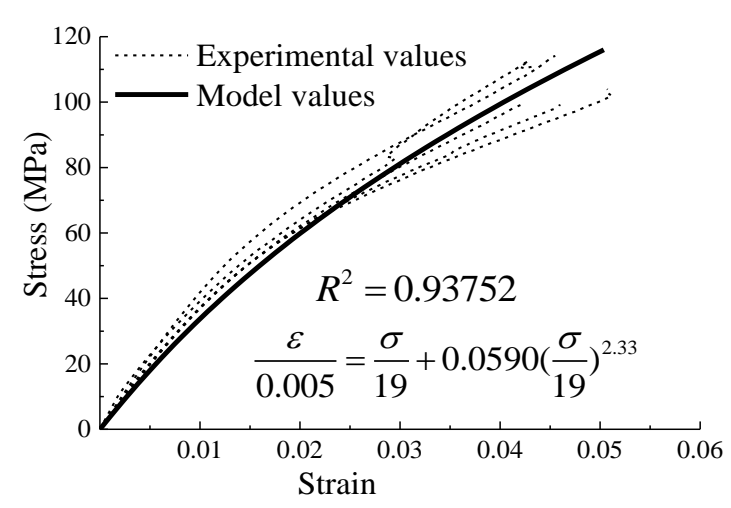

(c) Group ER

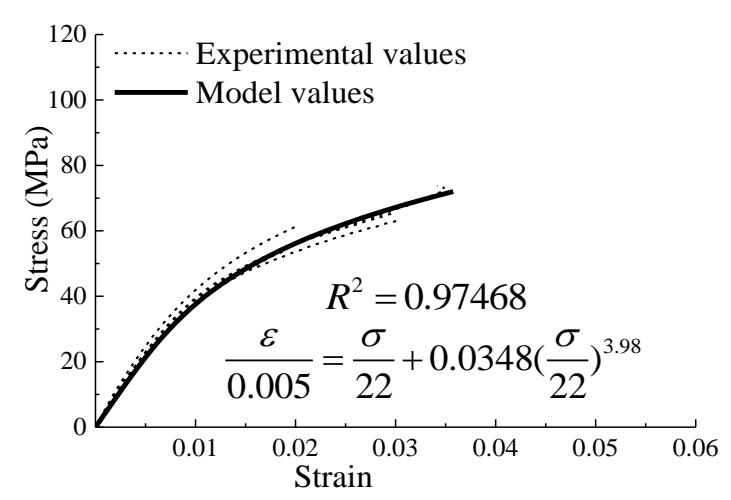

(b) Group MT

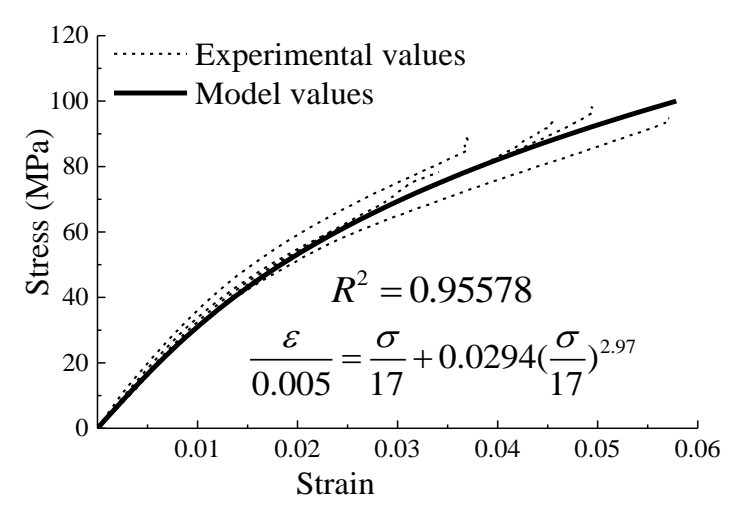

(d) Group MR

Fig. 19. Comparison between experimental values and model values

\section{Conclusions}

To evaluate how the cutting position and compression direction influence the local compression mechanical properties of large-scale parallel bamboo strand lumber (PBSL), 20 specimens were tested and the experimental results were analyzed. The following conclusions are drawn.

(1) The failure of all specimens has gone through the elastic stage, elastic-plastic stage, and failure stage. For the middle specimens tangentially loaded, the failure belonged to ductile failure. For other group specimens, the failure belonged to quasi-brittle failure. The failure of the specimen loaded radially was more serious than that of the specimen loaded tangentially.

(2) The failure of the specimen was caused by the deformation perpendicular to the loading direction. The failure of the specimen tangentially loaded was mainly caused by deformation perpendicular to grain direction, while the specimen radially loaded was not only caused by the deformation perpendicular to 
grain direction but also the deformation parallel to bamboo fiber direction grain direction.

(3) The values for elastic modulus, stiffness, ultimate strength and Poisson's ratio of the end specimen were higher than those of the middle specimen. The values for elastic modulus, stiffness and Poisson's ratio of the specimens loaded tangentially were higher than those of the specimens loaded radially but the ultimate strength values for specimens loaded tangentially were lower than those for the specimens loaded radially. And the ductility of the middle specimens was better than that of the end specimens.

(4) The load-displacement relationship model of the local compressive of PBSL was proposed according to the analysis of the test data. Based on the Ramberg-Osgood relation (ROR), the stress-strain relationship models for PBSL under local compression were proposed and compared with the test data.

Acknowledgment: The research work presented in this paper is supported by the National Natural Science Foundation of China (No. 51878354 \& 51308301), the Natural Science Foundation of Jiangsu Province (No. BK20181402 \& BK20181402), Postgraduate Research \&Practice Innovation Program of Jiangsu Province (No. KYCX20_0885), Six talent peak high-level projects of Jiang-su Province (No. JZ-029), and a Project Funded by the Priority Academic Program Development of Jiangsu Higher Education Institutions. Any research results expressed in this paper are those of the writer(s) and do not necessarily reflect the views of the foundations. The writers gratefully acknowledge Zhen WANG, Hang Li, Xiaoyan Zheng, Shaoyun Zhu, Liqing Liu, Dunben Sun, Jing Cao, Yanjun Liu and others from the Nanjing Forestry University for helping with the tests.

\section{References}

[1] X. Li, M. Ashraf, M. Subhani, P. Kremer, B. Kafle, K. Ghabraie. Experimental and numerical study on bending properties of heterogeneous lamella layups in cross laminated timber using Australian Radiata Pine, Construction and Building Materials. 247 (2020) 118525.

[2] Z. Wang, W. Xie, Z. Wang, Cao. Y, Strain method for synchronous dynamic measurement of elastic, shear modulus and Poisson's ratio of wood and wood composites, Construction and Building Materials. 182 (2018) 608-617.

[3] P. Van der Lugt, A. A. J. F. Van den Dobbelsteen, J. J. A. Janssen, An environmental, economic and practical assessment of bamboo as a building material for supporting structures, Construction and building materials. 20 (9) (2006) 648-656.

[4] G. Chen, B. He, Stress-strain constitutive relation of OSB under axial loading: An experimental investigation, Bioresources. 12(3) (2017) 6142-6156.

[5] D. Yang, H. Li, Z. Xiong, L. Mimendi, R. Lorenzo, I. Corbi, O. Corbi, C. Hong, Mechanical properties of laminated bamboo under off-axis compression, Composites Part A: Applied Science and Manufacturing. 138 (2020) 106042.

[6] C. P. Takeuchi, M. Estrada, D. L. Linero, Experimental and numerical modeling of shear behavior of laminated Guadua bamboo for different fiber directions, Construction and Building Materials. 177 (2018) 23-32.

[7] L. Molari, L. Mentrasti, M. Fabiani, Mechanical characterization of five species of Italian bamboo, Structures. 24 (2020) 59-72.

[8] B. Sharma, A. Gatoo, M. Bock, H, Mulligan, M. Ramage, Engineered bamboo: state of the art, Proceedings of the Institution of Civil Engineers-Construction Materials. 268 (2) (2015) 57-67.

[9] A. Muhammad, M. R. Rahman, S. Hamdan, K. Sanaullah. Recent developments in bamboo fiber-based composites: A review, Polymer Bulletin. 76 (5) (2019) 2655-2682.

[10] Y. Xiao, Z. Li, Y. Wu, B. Shan, Research and engineering application progress of laminated bamboo structure, Building Structure. 48 (10) (2018) 84-88.

[11] G. Quaranta, C. Demartino, Y. Xiao, Experimental dynamic characterization of a new composite glubam-steel truss structure, Journal of Building Engineering. 25 (2019) 100773. 
[12] M. Penellum, B. Sharma, D. U. Shah, R. M. Foster, M. H. Ramage, Relationship of structure and stiffness in laminated bamboo composites, Construction and Building Materials. 165 (2018) 241-246.

[13] A. Kumar, P. Ryparovà, B. Kasal, S. Adamopoulos, P. Hajek, Resistance of bamboo scrimber against white-rot and brown-rot fungi, Wood Material Science \& Engineering. 15 (1) 2020 57-63.

[14] M. Mahdavi, P. L. Clouston, S. R. Arwade, A low-technology approach toward fabrication of laminated bamboo lumber, Construction and Building Materials. 29 (2012) 257-262.

[15] C. S. Verma, V. M. Chariar, Stiffness and strength analysis of four layered laminate bamboo composite at macroscopic scale, Composites Part B: Engineering. 45 (1) 2013 369-376.

[16] J. F. Correal, J. S. Echeverry, F. Ramírez, L. E. Yamín, Experimental evaluation of physical and mechanical properties of Glued Laminated Guadua angustifolia Kunth, Construction and Building Materials. 73 (2014) 105-112.

[17] A. Sinha, D. Way, S. Mlasko, Structural performance of glued laminated bamboo beams, Journal of Structural Engineering. 140 (1) (2014) 04013021.

[18] B. Sharma, A. Gatóo, M. H. Ramage, Effect of processing methods on the mechanical properties of engineered bamboo, Construction and Building Materials. 83 (2015) 95-101.

[19] Y. P. Ren, H. Z. Liu, W. J. Guo, Y. P. Dai, Adhesion Performance Comparison of Structural Bamboo Scrimber with Two Kinds of Resin, Forest Engineering. 35 (2) (2019) 45-49.

[20] I. F. Ridzqo, D. Susanto, T. H. Panjaitan, N. Putra, Sustainable Material: Development Experiment of Bamboo Composite Through Biologically Binding Mechanism, IOP Conference Series: Materials Science and Engineering. 713 (1) (2020) 012010.

[21] Y. Yu, R. Liu, Y. Huang, F. Meng, W. Yu, Preparation, physical, mechanical, and interfacial morphological properties of engineered bamboo scrimber, Construction and Building Materials. 157 (2017) 1032-1039.

[22] A. Kumar, T. Vlach, L. Laiblova, M. Hrouda, B. Kasal, J. Tywoniak, P. Hajek, Engineered bamboo scrimber: Influence of density on the mechanical and water absorption properties, Construction and Building Materials. 127 (2016) 815-827.

[23] H. T. Li, H. Z. Zhang, Z. Y. Qiu, J. W. Su, D. D. Wei, R. Lorenzo, C. G. Yuan, H. Z. Liu, C. G. Zhou, Mechanical Properties and Stress Strain Relationship Models for Bamboo Scrimber, Journal of Renewable Materials. 8 (1) (2020) 13-27.

[24] H. T. Li, Z. Y. Qiu, G. Wu, D. D. Wei, R. Lorenzo, C. G. Yuan, H. Z. Zhang, R. Liu, Compression behaviors of parallel bamboo strand lumber under static loading, Journal of Renewable Materials. 7 (7) 2019 583-600.

[25] B. Sharma, A. Gatoo, M. Bock, M. Ramage, Engineered bamboo for structural applications, Construction and Building Materials. 81 (2015) 66-73.

[26] W. Shangguan, Y. Zhong, X. Xing, R Zhao, H Ren, Strength models of bamboo scrimber for compressive properties, Journal of wood science. 61 (2) (2015) 120-127.

[27] W. Shangguan, Y. Gong, R. Zhao, H. Ren, Effects of heat treatment on the properties of bamboo scrimber, Journal of wood science. 62 (5) (2016) 383-391.

[28] N. Nugroho, N. Ando, Development of structural composite products made from bamboo I: fundamental properties of bamboo zephyr board, Journal of wood science. 46 (1) (2000) 68-74.

[29] N. Nugroho, N. Ando, Development of structural composite products made from bamboo II: fundamental properties of laminated bamboo lumber, Journal of wood science. 47 (3) (2001) 237-242.

[30] Y. Zhong, H. Q. Ren, Z. H. Jiang, Effects of temperature on the compressive strength parallel to the grain of bamboo scrimbe, Materials. 9 (6) 2016436.

[31] M. Xu, Z. Cui, Z, Chen, J, Xiang, Experimental study on compressive and tensile properties of a bamboo scrimber at elevated temperatures, Construction and Building Materials. 151 (2017) 732-741.

[32] P. Malanit, M. C. Barbu, A. Frühwald, Physical and mechanical properties of oriented strand lumber made from an Asian bamboo (Dendrocalamus asper Backer), European Journal of Wood and Wood Products. 69 (1) 
(2011) 27-36.

[33] J. W. Zhou, D. S. Huang, Y. R. Shen, Experiments on partial compression bearing capacity parallel to the grain of bamboo strand scrimber, China Science Paper. 13 (13) (2018) 1462-1466.

[34] J. W. Zhou, D. S. Huang, Y. R. Shen, Experiments of partial compression bearing capacity perpendicular to the grain of bamboo scrimber, Journal of Forestry Engineering. 3 (01) (2018) 123-127.

[35] C. Cheng, H. T. Li, D. D. Wei, R. Lorenzo, C. G. Yuan, Mechanical performance of parallel bamboo strand lumber columns under axial compression: Experimental and numerical investigation, Construction and Building Materials. 231 (2020) 117168.

[36] M. Aschheim, L. M. Gil-Martín, E. Hernández-Montes, Engineered bamboo I-joists, Journal of structural engineering. 136 (12) 2010 1619-1624.

[37] T. A. C. M. Van der Put, Derivation of the bearing strength perpendicular to the grain of locally loaded timber blocks, HolzalsRoh- und Werkstoff. 66 (6) 2008 409-417.

[38] A. J. M. Leijten, H. J. Larsen, T. A. C. M. Van der Put, Structural design for compression strength perpendicular to the grain of timber beams, Construction and Building Materials. 24 (3) (2010) 252-257.

[39] A. J. M. Leijten, A. J. M. Jorissen, B. J. C. De Leijer, The local bearing capacity perpendicular to the grain of structural timber elements, Construction \& Building Materials. 27 (1) (2012) 54-59.

[40] A. J. M. Leijten, The bearing strength capacity perpendicular to the grain of Norway spruce - Evaluation of three structural timber design models, Construction and Building Materials. 105 (2016) 528-535.

[41] B. Madsen, R. F. Hooley, C. P. Hall, A design method for bearing stresses in the wood, Canadian Journal of Civil Engineering. 9 (2) (1982) 338-349.

[42] Min-Chyuan Yeh, Yu-li Lin. Finger joint performance of structural laminated bamboo member. Journal of Wood Science, 2012, 58(2): 120-127.

[43] W. Ramberg, W. R. Osgood, Description of stress-strain curves by three parameters, National Bureau of Standards, Washington DC. 1943. 